\title{
ИЗУЧЕНИЕ ОКИСЛИТЕЛЬНОГО РАДИОЛИЗА БИОЛОГИЧЕСКИ АКТИВНЫХ СОЕДИНЕНИЙ. РЕАКЦИОННАЯ СПОСОБНОСТЬ ЗАМЕЩЕННЫХ ФЕНОЛОВ
}

\author{
(Представил М. Губерериц)
}

В состав промышленных отходов, загрязняющих биосферу, часто входят фенолы, обладающие физиологической (токсической или канцерогенной) активностью. Фенолы, как известно, легко окисляются, и поэтому многие методы обезвреживания их базируются на различных окислительных процессах. Закономерности радиолиза фенолов освещены в литературе с теоретической (установление элементарного механизма) $\left[{ }^{1-2}\right]$, а также и с более прикладной $\left.{ }^{3}\right]$ точки зрения, однако сделано это на примере окисления тех представителей, которые нехарактерны для сточных вод сланцевой промышленности. Поэтому цель настоящего исследования - установление принципиальной возможности применения окислительного радиолиза как метода обезвреживания фенольных сточных вод. Для этого было необходимо изучить кинетические закономерности радиолиза ряда замещенных фенолов и сравнить полученные данные с результатами наших предыдущих опытов по другим процессам окисления фенолов.

\section{Методика эксперимента}

Кинетика окислительного радиолиза для 43 замещенных фенолов (табл. 1, температуры плавления корригированы) исследована в насыщенных молекулярным кислородом растворах $96 \%$-ного этанола и воде (концентрация $10^{-3}$ и $10^{-4} \mathrm{M}$ ) при температуре $18 \pm 1^{\circ} \mathrm{C}$. Мощность дозы $\gamma$-излучения ${ }^{60} \mathrm{Co}$ (установка Луч-1, Институт экспериментальной биологии АН ЭССР) составляла в среднем 4 рад/c по дозиметрии Фрике [4]. Для расчета эффективных констант скоростей радиолиза фенолов в качестве аргумента использована доза подведенной к системе энергии [5]. Концентрация фенолов определена после реакции сочетания с $n$-аминоантипирином $\left.{ }^{6}\right]$ фотоколориметрически на приборе ФЭК-56ПМ.

\section{Результаты и обсуждение}

Эффективные константы скорости окислительного радиолиза изученных фенолов в растворе этанола приведены в табл. 1, для водных растворов - в [5]. В обоих растворителях реакционные серии с концентрацией $10^{-3}$ и $10^{-4} M$ хорошо сопоставимы между собой (коэффициент корреляции констант скоростей, $r$ колеблется в пределах 
Таблица 1

Эффективные константы скорости, $k \pm 0,1$ молек./эB, окислительного радиолиза фенолов в $96 \%$-ном этаноле при $18{ }^{\circ} \mathrm{C}$

\begin{tabular}{|c|c|c|c|c|c|}
\hline \multirow{2}{*}{$\begin{array}{c}\text { Заместители в } \\
\text { бензольном кольце }\end{array}$} & \multicolumn{2}{|c|}{$\lg k+3$} & \multirow{2}{*}{$\begin{array}{c}\text { Заместители в } \\
\text { бензольном кольце }\end{array}$} & \multicolumn{2}{|c|}{$\lg k+3$} \\
\hline & $10^{-3} M$ & $10^{-4} M$ & & $10^{-3} M$ & $10^{-4} M$ \\
\hline $\mathrm{H}$ & 1,29 & 0,98 & $2,4,6-\left(\mathrm{CH}_{3}\right)_{3}$ & 1,36 & 0,85 \\
\hline $3-\mathrm{CH}_{3}$ & 1,36 & 1,07 & $2,4-\left[\mathrm{C}\left(\mathrm{CH}_{3}\right)_{3}\right]_{2}$ & 1,10 & 0,74 \\
\hline $3-\mathrm{C}\left(\mathrm{CH}_{3}\right)_{3}$ & 1,34 & 0,97 & $2,6-\left[\mathrm{C}\left(\mathrm{CH}_{3}\right)_{3}\right]_{2}-4-\mathrm{CH}_{3}$ & 1,60 & 1,18 \\
\hline $3,5-\left(\mathrm{CH}_{3}\right)_{2}$ & 1,34 & 0,97 & $2,4,6-\left[\mathrm{C}\left(\mathrm{CH}_{3}\right)_{3}\right]_{3}$ & 1,77 & 1,20 \\
\hline $3-\mathrm{CH}_{3}-5-\mathrm{C}_{2} \mathrm{H}_{5}$ & 1,23 & 0,91 & $2,6-\left(\mathrm{OCH}_{3}\right)_{2}$ & 1,38 & 0,86 \\
\hline $4-\mathrm{CH}_{3}$ & 1,14 & 0,72 & $2-\mathrm{OCH}_{3}-4-\mathrm{CH}_{3}$ & 1,32 & 0,81 \\
\hline $4-\mathrm{CH}\left(\mathrm{CH}_{3}\right)_{2}$ & 0,94 & 0,60 & 2-OH & 1,06 & 0,72 \\
\hline 4- $\left(\mathrm{CH}_{2}\right)_{2} \mathrm{CH}_{3}$ & 0,94 & 0,61 & 3-OH & 1,32 & 0,90 \\
\hline $4-\mathrm{CH}\left(\mathrm{CH}_{3}\right) \cdot\left(\mathrm{C}_{2} \mathrm{H}_{5}\right)$ & 0,88 & 0,46 & $3-\mathrm{OH}-5-\mathrm{CH}_{3}$ & 1,08 & 0,68 \\
\hline $4-\mathrm{C}\left(\mathrm{CH}_{3}\right)_{3}$ & 1,03 & 0,58 & $3-\mathrm{OH}-5-\left(\mathrm{CH}_{2}\right)_{6} \mathrm{CH}_{3}$ & 1,01 & 0,63 \\
\hline $4-\mathrm{C}\left(\mathrm{C}_{2} \mathrm{H}_{5}\right)_{2}\left(\mathrm{C}_{3} \mathrm{H}_{7}\right)$ & 0,64 & 0,33 & $3-\mathrm{OH}-5-\left(\mathrm{CH}_{2}\right)_{9} \mathrm{CH}_{3}$ & 1,11 & 0,78 \\
\hline $4-\mathrm{CH}_{2} \mathrm{C}_{6} \mathrm{H}_{5}$ & 1,04 & 0,61 & $3-\mathrm{OH}-2-\mathrm{CH}_{3}$ & 1,31 & 0,90 \\
\hline $3,4,5-\left(\mathrm{CH}_{3}\right)_{3}$ & 1,16 & 0,67 & $3-\mathrm{OH}-2-\left(\mathrm{CH}_{2}\right)_{2} \mathrm{CH}_{3}$ & 1,38 & 1,02 \\
\hline $2-\mathrm{CH}_{3}$ & 1,10 & 0,83 & $3-\mathrm{OH}-2-\left(\mathrm{CH}_{2}\right)_{3} \mathrm{CH}_{3}$ & 1,13 & 0,68 \\
\hline $2-\mathrm{CH}_{2}-\mathrm{CH}=\mathrm{CH}_{2}$ & 1,19 & 0,76 & $3-\mathrm{OH}-2-\left(\mathrm{CH}_{2}\right)_{5} \mathrm{CH}_{3}$ & 1,32 & 0,76 \\
\hline $2-\left(\mathrm{CH}_{2}\right)_{2} \mathrm{CH}_{3}$ & 1,18 & 0,78 & $3-\mathrm{OH}-2-\left(\mathrm{CH}_{2}\right)_{8} \mathrm{CH}_{3}$ & 1,51 & 1,05 \\
\hline $2-\mathrm{CH}\left(\mathrm{CH}_{3}\right)\left(\mathrm{C}_{2} \mathrm{H}_{5}\right)$ & 1,16 & 0,76 & $3-\mathrm{OH}-2-\left(\mathrm{CH}_{2}\right)_{5} \mathrm{CH}_{3}-5-\mathrm{CH}_{3}$ & 1,56 & 1,05 \\
\hline $2-\mathrm{CH}_{2} \mathrm{C}_{6} \mathrm{H}_{5}$ & 1,15 & 0,71 & $3-\mathrm{OH}-2-\left(\mathrm{CH}_{2}\right)_{8} \mathrm{CH}_{3}-5-\mathrm{CH}_{3}$ & 1,36 & 0,92 \\
\hline $2,5-\left(\mathrm{CH}_{3}\right)_{2}$ & 1,38 & 1,09 & $3-\mathrm{OH}-4,6-\left[\mathrm{C}\left(\mathrm{CH}_{3}\right)_{3}\right]_{2}$ & 1,18 & 0,67 \\
\hline $2,3-\left(\mathrm{CH}_{3}\right)_{2}$ & 1,18 & 0,91 & $3-\mathrm{OH}-5-\mathrm{OH}$ & 1,62 & 1,20 \\
\hline $\begin{array}{l}2,6-\left(\mathrm{CH}_{3}\right)_{2} \\
2,3,5-\left(\mathrm{CH}_{3}\right)_{3}\end{array}$ & $\begin{array}{l}1,39 \\
1,21\end{array}$ & $\begin{array}{l}1,01 \\
1,14\end{array}$ & $2-\mathrm{OH}-6-\mathrm{OH}$ & 1,43 & 0,95 \\
\hline & & & & & \\
\hline
\end{tabular}

При м е ч а н и : Алкилрезорцины синтезированы [ $\left.{ }^{9}\right]$ и любезно предоставлены нам Ю. Э. Лилле.

0,92-0,97 и наклон близок к единице). Поэтому можно предположить, что полученные нами эффективные константы относятся к одной и той же лимитирующей стадии процесса и являются функциями одних и тех же факторов строения фенола. Для выяснения количественной взаимосвязи структуры фенолов и их реакционной способности в процессе окислительного радиолиза нами применен метод корреляционного анализа. Экспериментальные данные (табл. 1 и [5]) были обработаны в соответствии с известными уравнениями Гаммета-Тафта и ЮкаваЦуно в форме, предложенной В. А. Пальмом [7], где

$$
\begin{array}{r}
\lg k=\lg k_{0}+\varrho^{0} \Sigma \sigma^{0}+\varrho_{R} \Sigma \sigma_{R}^{+}, \\
\Sigma \sigma^{0}=\Sigma \sigma_{m}^{0}+\Sigma \sigma_{0}^{0}+\sigma_{p}^{0}, \quad \sigma_{R}^{+}=\sigma^{+}-\sigma^{0} .
\end{array}
$$

Обработка данных проведена методом наименьших квадратов на ЭВМ «Наири-2». Константы заместителей $\sigma^{+}$и $\sigma^{0}$ взяты из [8].

Результаты корреляционного анализа данных представлены в табл. 2, откуда видно, что эффективные константы скорости инициированного радиолизом окисления фенолов обнаруживают хорошую корреляцию по уравнению Гаммета-Тафта только в случае мета-заместителей (1). Введение орто- и пара-заместителей значительно ухудшает корреляцию (2), что свидетельствует о наличии резонансного влияния заместителей. Последнее подтверждается хорошей корреляцией по 
Таблица 2

Параметры в корреляционных уравнениях: реакционная способность-структура фенолов. Реакционным центром принято в уравнениях $(1-5)$ гидроксильная группа, а в $(6,7)-$ орто-положение ядра. Концентрация $(1-3 ; 5 ; 7)-1 \cdot 10^{-4} \boldsymbol{M}$;

$(4,6)-1 \cdot 10^{-3} M$

\begin{tabular}{|c|c|c|c|c|c|}
\hline \multirow{2}{*}{$\begin{array}{c}\text { № } \\
\text { урав- } \\
\text { нения }\end{array}$} & \multirow{2}{*}{$\begin{array}{c}\text { Раствори- } \\
\text { тель }\end{array}$} & \multirow{2}{*}{$\begin{array}{l}\text { Положение } \\
\text { заместителя }\end{array}$} & \multicolumn{2}{|c|}{ Чувствительность } & \multirow{2}{*}{$r$} \\
\hline & & & $\mathrm{Q}^{0}$ или $\mathrm{Q}^{*}$ & $Q_{R}$ & \\
\hline 1 & вода & мета & $0,78 \pm 0,07$ & - & 0,985 \\
\hline 2 & вода & орто, мета, пара & $0,41 \pm 0,07$ & - & 0,794 \\
\hline 3 & вода & орто, мета, пара & $0,61 \pm 0,17$ & $-0,64 \pm 0,37$ & 0,998 \\
\hline 4 & этанол & мета & $-0,94 \pm 0,36$ & - & 0,698 \\
\hline 5 & этанол & мета & $-0,93 \pm 0,43$ & - & 0,633 \\
\hline 6 & этанол & орто & $0,42 \pm 0,03$ & - & 0,997 \\
\hline 7 & этанол & орто & $0,41 \pm 0,06$ & - & 0,909 \\
\hline
\end{tabular}

уравнению Юкава-Цуно (3). Однако в отличие от водных растворов, в растворе этанола не наблюдалось взаимосвязи реакционной способности фенолов с индукционными константами $(4,5)$ даже с учетом эффекта сопряжения (данные здесь не приведены). По данным [ $\left.{ }^{2}\right]$, гидроксилирование в молекуле фенола может происходить в ортоположении ароматического кольца. Исходя из этого, нами проверена реакционная способность незамещенного углеродного атома как реакционного центра и сопоставлены эффективные константы скорости радиолиза фенолов с константами $\sigma^{*}$ Тафта (при наличии соответствующих данных) соседнего заместителя (табл. 2). Результаты корреляционного анализа $(6,7)$ свидетельствуют о том, что образующиеся при радиолизе этанола радикалы $\left.{ }^{10}\right]$ присоединяются к ароматическому ядру в орто-положении относительно гидроксильной группы, в то время как в водном растворе лимитирующей радиолиз фенолов стадией был, по-видимому, отрыв протона от гидроксила. Нами исследован радиолиз в этаноле производных 1,3-диоксифенолов, т. е. алкилрезорцинов, которые характерны для сланцевых сточных вод. На рисунке показано изменение эффективных констант скоростей окислительных фотолиза и радиолиза от длины 2-алкильной цепи фенола.

Зависимость констант скорости окислительного радиолиза (1 $\left.\lg k^{\prime}+3,2-\lg k^{\prime \prime}+3\right)$ и фотолиза $\left(3-\lg k_{1}+\right.$ $\left.+4, \quad 4-\lg k_{2}+5\right)$ 2-алкилрезорцинов в растворе этанола от числа углеродных атомов в алькильной цепи.

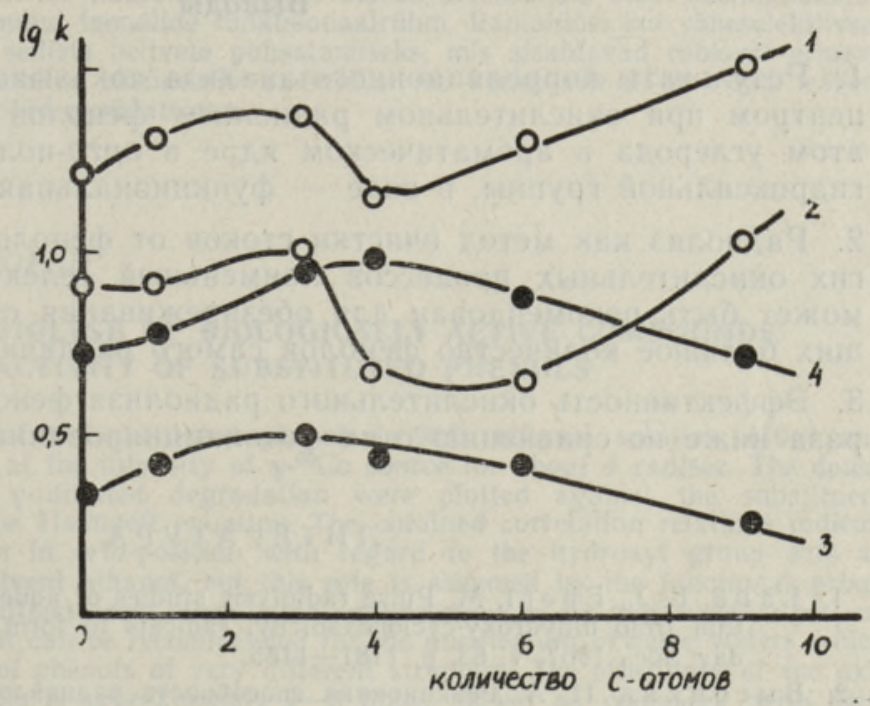


Если в случае фотолиза индукционные эффекты заместителей явно увеличивают скорость окисления до $\mathrm{C}_{3}-\mathrm{C}_{4}$, а в дальнейшем преобладающими становятся стерические эффекты, снижающие скорость, то наблюдающийся при радиолизе экстремум при $\mathrm{C}_{3}-\mathrm{C}_{4}$ и дальнейшее увеличение скорости с удлинением углеродной цепи требует специального исследования. Полученные нами эффективные константы скорости и значения параметров в корреляционных уравнениях окислительного радиолиза фенолов в воде позволяют дать сравнительную оценку эффективности и избирательности изучаемого модельного процесса очистки от фенолов. Судя по константам чувствительности $(\varrho<1$, табл. 2), окислительный радиолиз принадлежит к неселективным процессам и может быть рекомендован для очистки стоков, содержащих большое число фенолов разного строения.

Ранее нами исследовались также процессы биохимического окисления $\left[{ }^{11}\right]$, автоокисления $\left[{ }^{12}\right]$ и фотолиза [5] фенолов. Из сравнения абсолютных эффективных констант скоростей окислений фенолов во всех перечисленных процессах следует, что для простых одноатомных фенолов наиболее эффективна биохимическая деградация на устойчиво адаптированных активных илах, за ней следует окислительный фотолиз, радиолиз и автоокисление. Ориентировочное соотношение средней эффективности этих процессов, исходя из скорости превращения фенолов, составляет $100: 10: 3: 1$. В случае многоатомных фенолов, которые легко подвергаются автоокислению, скорость отдельных процессов различается незначительно, хотя последовательность сохраняется. Нами исследовано также изменение токсичности реакционных смесей в ходе окисления (на теплокровных животных) и установлено, что токсическая активность фенола и орцина снижается параллельно снижению их концентрации в процессе окислительного радиолиза, в то время как в процессе автоокисления при ограниченном доступе кислорода токсичность раствора даже повышается $\left[{ }^{13}\right]$. Следовательно, в результате окислительного радиолиза действительно достигается обезвреживание фенольных стоков.

Авторы выражают благодарность М. Я. Губергрицу и А. В. Туулметс за ценные советы и поддержку в работе.

\section{Выводы}

1. Результаты корреляционного анализа показывают, что реакционным центром при окислительном радиолизе фенолов в этаноле является атом углерода в ароматическом ядре в орто-положении относительно гидроксильной группы, в воде - функциональная группа фенолов.

2. Радиолиз как метод очистки стоков от фенолов отличается от других окислительных процессов наименьшей селективностью и поэтому может быть рекомендован для обезвреживания сточных вод, содержащих большое количество фенолов самого различного строения.

3. Эффективность окислительного радиолиза фенолов в среднем в $2-3$ раза ниже по сравнению с их фотоинициированным окислением.

\section{ЛИТЕРАТ У РА}

1. L a n d, E. J., E be rt, M. Pulse radiolysis studies of aqueous phenol. Water elimination from dihydroxy-cyclohexadienyl radicals to form phenoxyl. - Trans. Faraday Soc., 1967 , v. 63 , p. $1181-1185$.

2. В ысоцкая Н. А. Реакционная способность радикалов $\dot{\mathrm{O}}, \dot{\mathrm{O}}-\dot{H}_{2} \dot{\mathrm{O}}_{2}$ и атомов 
кислорода в водных растворах ароматических соединений. - Успехи химии, 1973, вып. 10, с. $1843-1853$.

3. Брусенцева С. А., При буш А. Г., Шубин В. Н., Долин П. И. Радиолиз водных растворов фенола. - Хим. высок. энергий, 1973, т. 5, № 1, с. 83.

4. С в ал лоу А. Радиационная химия органических соединений. М., 1973, с. 77.

5. Кирсо У., Уйбопуу Х., Туулметс А., Губергриц М., Лилле Ю. Исследование кинетики инициированного окисления замещенных фенолов в водном растворе. - Реакц. способ. орг. соед., 1973, т. 10, с. $625-636$.

6. К и р со У. Э. Определение различных фенолов реакций с 4-аминоантипирином. Изв. АН ЭССР. Хим., Геол., 1977, т. 26, с. $22-27$.

7. П альм В. А. Основы количественной теории органических реакций. Л., 1967, c. 194 .

8. Справочник химика, М.-Л., 1965, т. 3, с. 959.

9. Лилле Ю. Э., Би т те р Л. А. Способ получения алкилрезорцинов. - Открытия, изобрет., пром. образцы, товарн. знаки, 1971 , № 48, с. 93.

10. Пше жецкий С. Я. Механизм и кинетика радиационно-химических реакций. M., 1968 , с. 232.

11. Кирсо У. Э., Берновская Н. А., Губергриц М. Я. Реакционная способность фенолов в процессе биохимического окисления в моделях сточных вод. - Хим. тверд. топл., 1973, № 2, с. $100-105$.

12. К и рсо У. Э., Г у берг риц М. Я. Кинетика и макромеханизм окисления фенолов различного строения молекулярным кислородом в воднощелоч. среде. Ж. прикл. химии, 1972 , т. 45 , с. $835-839$.

13. К и рсо У., Велдре И. Токсичность продуктов деградации фенолов в зависимости от макромеханнзма процесса окисления. - Изв. АН ЭССР. Хим.. Геол., 1971, т. 20 , с. $26-30$.

$\begin{array}{cc}\text { Ннститут химии } & \text { Поступила в редакцию } \\ \text { Академии наук Эстонской ССР } & 9 / \mathrm{II} 1979\end{array}$

Uuve KIRSO, Helvi UIBOPUU

\section{BIOAKTIIVSETE UHENDITE OKSODEERIV RADIOLOUS. ASENDATUD FENOOLIDE REAGEERIMISVÕIME}

Töös on uuritud 43 asendatud fenooli oksüdeerivat radiolüüsi $96 \%$-lises etanooli vesilahuses (konts. $10^{-3}$ ja $10^{-4} \mathrm{mool} / \mathrm{l}$ ), ${ }^{60} \mathrm{Co} \gamma$-kiirguse keskmine intensiivsus $4 \mathrm{rad} / \mathrm{sek}$. Fenoolide kiiruskonstandid on vastandatud asendajate konstantidega Hammetti vōrrandi abil. Korrelatsioonanalüüsi tulemused näitavad, et fenoolide oksüdeerival radiolüüsil etanoolis on reaktsiooni tsentriks hüdroksüülrühma suhtes ortoasendis olev süsinikuaatom, vees toimuva radiolüüsi puhul fenoolide funktsionaalrühm. Radiolüüsi kui väheselektiivset protsessi võib soovitada selliste heitvete puhastamiseks, mis sisaldavad rohkesti erineva struktuuriga fenoole. Fenoolide oksüdeeriv radiolüüs on keskmiselt $2-3$ korda vähem efektiivne kui fotoinitsieeritud oksüdatsioon.

\section{Uuve KIRSO, Helvi UIBOPUU}

\section{OXIDATIVE RADIOLYSE OF BIOLOGICALLY ACTIVE COMPOUNDS. REACTIVITY OF SUBSTITUTED PHENOLS}

The oxidative radiolyse of 43 substituted phenols in $96 \%$ ethanol solution $\left(10^{-3}\right.$ and $10^{-4} \mathrm{~mol} / \mathrm{l}$ ) was studied, at the intensity of $\gamma^{-60} \mathrm{Co}$ source for about $4 \mathrm{rad} / \mathrm{sec}$. The determined rate constants of $\gamma$-initiated degradation were plotted against the substituent constants values using the Hammett equation. The obtained correlation relations indicated that the carbon atom in orto-position with regard to the hydroxyl group acts as reaction centre in the solvent ethanol, but this role is assumed by the functional group of phenol. The radiolyse differs from other oxidation processes by its non-selective properties and because of that it can be recommended for the purification of waste waters which contain a large number of phenols of very different structure. The effectivity of the oxidative radiolyse of phenols is approximately 2-3 times slower as compared with their photoinitiated oxidation. 